Keywords: Roughness, displacement height, H-Area, atmospheric dispersion

Retention: Permanent

\title{
Roughness Lengths for the Savannah River Site
}

A.H. Weber, R.J. Kurzeja, and C.H. Hunter

March, 2012

Savannah River National Laboratory

Savannah River Nuclear Solutions, LLC

Aiken, SC 29808

Prepared for the U.S. Department of Energy under contract number DE-AC09-08SR22470. 
SRNL-STI-2012-00016

Revision 0 
SRNL-STI-2012-00016

Revision 0

\section{DISCLAIMER}

This work was prepared under an agreement with and funded by the U.S. Government. Neither the U.S. Government or its employees, nor any of its contractors, subcontractors or their employees, makes any express or implied:

1. warranty or assumes any legal liability for the accuracy, completeness, or for the use or results of such use of any information, product, or process disclosed; or

2. representation that such use or results of such use would not infringe privately owned rights; or

3. endorsement or recommendation of any specifically identified commercial product, process, or service.

Any views and opinions of authors expressed in this work do not necessarily state or reflect those of the United States Government, or its contractors, or subcontractors.

\section{Printed in the United States of America}

Prepared for

U.S. Department of Energy 


\section{REVIEWS AND APPROVALS}

AUTHOR:
A.H. Weber, Atmospheric Technologies Group
Date

AUTHOR:

R. J. Kurzeja, Atmospheric Technologies Group Date

$\underline{\text { AUTHOR: }}$

C. H. Hunter, Atmospheric Technologies Group Date

TECHNICAL

REVIEW:
B. J. Viner, Atmospheric Technologies Group
Date

ADDITIONAL REVIEWER:

A. M. Vincent, N\&CSE Safety Programs Date

APPROVAL:

L. M. Chandler, Manager, Nonproliferation Technologies Date 


\section{ACKNOWLEDGEMENTS}

We gratefully acknowledge the help of S.R. Chiswell, M.J. Parker, J.T. Hamilton, R.L. Buckley and others in the Atmospheric Technologies Group at SRNL for their help and suggestions in data collection and writing this document. 


\section{EXECUTIVE SUMMARY}

Surface roughness values for the areas surrounding the $\mathrm{H}, \mathrm{D}$ and $\mathrm{N}$-Area meteorological towers were computed from archived 2010 meteorological data. These 15-minute-averaged data were measured with cup anemometers and bidirectional wind vanes (bivanes) $61 \mathrm{~m}$ above the surface. The results of the roughness calculation using the standard deviation of elevation angle $\sigma_{E}$, and applying the simple formula based on tree canopy height, gave consistent estimates for roughness around the H-Area tower in the range of 1.76 to $1.86 \mathrm{~m}$ (95\% confidence interval) with a mean value of $1.81 \mathrm{~m}$. Application of the $\sigma_{E}$ method for the $61-\mathrm{m}$ level at $\mathrm{D}$ and $\mathrm{N}$-Areas gave mean values of 1.71 and 1.81 with confidence ranges of $1.62-1.81$ and $1.73-1.88$ meters, respectively. Roughness results are azimuth dependent, and thus are presented as averages over compass sectors spanning 22.5 degrees. Calculated values were compared to other methods of determining roughness, including the standard deviation of the azimuth direction, $\sigma_{A}$, and standard deviation of the wind speed, $\sigma_{U}$. Additional data was obtained from a sonic anemometer at 61-m on the H-Area tower during a period of a few weeks in 2010. Results from the sonic anemometer support our use of $\sigma_{E}$ to calculate roughness.

Based on the H-Area tower results, a surface roughness of $1.8 \mathrm{~m}$ using is recommended for use in dispersion modeling applications that consider the impacts of a contaminant release to individuals along the Site boundary. The canopy surrounding the H-Area tower is relatively uniform (i.e., little variance in roughness by upwind direction), and data supplied by the U.S. Forest Service at Savannah River show that the canopy height and composition surrounding the $\mathrm{H}$-Area tower is reasonably representative of forested areas throughout the SRS reservation.

For dispersion modeling analyses requiring assessments of a co-located worker within the respective operations area, recommended area-specific values range from $0.3 \mathrm{~m}$ for E Area to $0.7 \mathrm{~m}$ for A Area at the Savannah River National Laboratory. These area-specific values, summarized in Table 4-1, were determined using the Environmental Protection Agency's AERSURFACE computer algorithm. 


\section{TABLE OF CONTENTS}

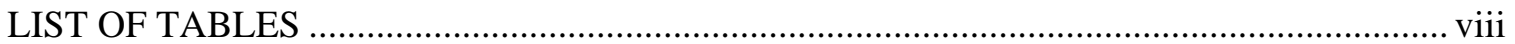

LIST OF FIGURES ..................................................................... vii

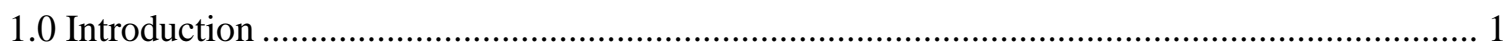

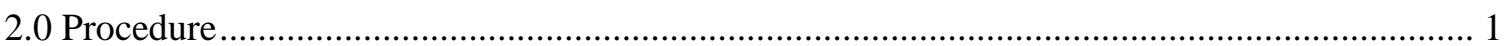

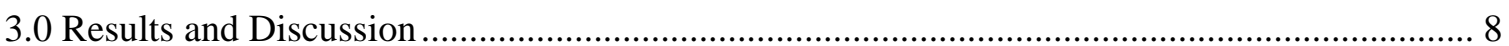

4.0 Additional Roughness Estimates for SRS Operations Areas ............................................... 15

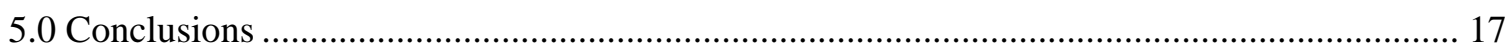

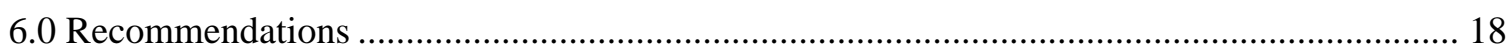

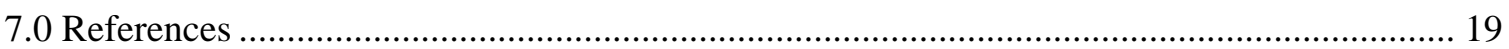

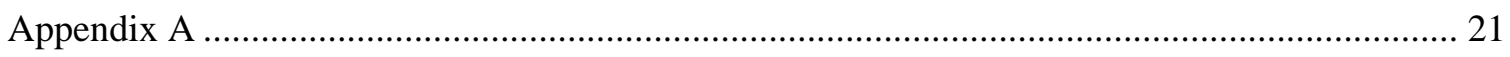

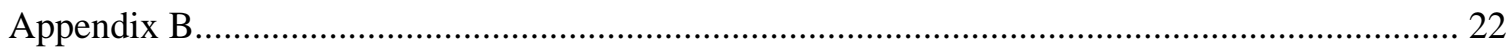




\section{LIST OF TABLES}

Table 3-1. Wind direction sector designations with lower and upper bounds for wind direction (proceeding clockwise). Wind direction is the direction from which the wind is blowing.

Table 3-2. Averaged roughness length over 15 wind direction sectors based on measurements from the H-Area tower, D-Area tower, and N-Area tower bivane and cup anemometers.

Table 3-3. Roughness mean, lower (95\%) confidence interval of the mean and upper (95\%) confidence interval of the mean for neutral cases, for 15 compass sectors using $\sigma_{E}$ measurements from the 61-m level of each tower (H-Area, D-Area and N-Area).

Table 3-4. Roughness mean, lower (95\%) confidence interval of the mean and upper (95\%) confidence interval of the mean for neutral cases, selected from sonic anemometer-derived- data from the 61-m level at H-Area.

Table 4-1. Roughness estimates for primary SRS operations areas.

Table A.1. Pasquill-Gifford categories based on implementation of the EPA (2000) method of determining stability categories using modified values of $\sigma_{E}$ and $\sigma_{A}$ for site roughness and height.

Table B-1. Lidar derived canopy height and composition data for SRS. Height data represent mean, 90th percentile, and 95th percentile values. Percent foliage/no foliage represents data collected during the winter season.

\section{LIST OF FIGURES}

Figure 2-1. Sample H-Area fetch for an easterly wind showing areas of most influence for a 43-m height, $5 \mathrm{~m} / \mathrm{s}$ wind speed, $0.50 \mathrm{~m} / \mathrm{s}$ friction velocity and neutral stability (Class D). The horizontal line in the figure is $3 \mathrm{~km}$. The $43-\mathrm{m}$ height $z_{m}$ represents the height of the H-Area tower measurement relative to the $18-\mathrm{m}$ displacement height.

Figure 2-2. Sample D-Area fetch for an easterly wind showing areas of most influence for a 43-m height, $5 \mathrm{~m} / \mathrm{s}$ wind speed, $0.50 \mathrm{~m} / \mathrm{s}$ friction velocity and neutral stability (Class D). The horizontal line in the figure is $3 \mathrm{~km}$. The $43-\mathrm{m}$ height $z_{m}$ represents the height of the D-Area tower measurement relative to the 18 -m displacement height.

Figure 2-3. Sample N-Area fetch for an easterly wind showing areas of most influence for a 43-m height, $5 \mathrm{~m} / \mathrm{s}$ wind speed, $0.50 \mathrm{~m} / \mathrm{s}$ friction velocity and neutral stability (Class D). The horizontal line in the figure is $3 \mathrm{~km}$. The $43-\mathrm{m}$ height $z_{m}$ represents the height of the $\mathrm{N}$-Area tower measurement relative to the 18 -m displacement height

Figure 3-1. Roughness value (m) by compass sector surrounding the H-Area tower computed from the three measurements of turbulence intensities: $\sigma_{u}$, (with $\mathrm{U}>5.0 \mathrm{~m} / \mathrm{s}$; magenta, solid curve), $\sigma_{A}$ (red, dashed curve) and $\sigma_{E}$ (green, dot-dashed curve). 
Figure 3-2 Roughness value $(\mathrm{m})$ by compass sector surrounding the D-Area tower computed from the three measurements of turbulence intensities: $\sigma_{u}$, (with $\mathrm{U}>5.0 \mathrm{~m} / \mathrm{s}$; magenta, solid curve), $\sigma_{A}$ (red, dashed curve) and $\sigma_{E}$ (green, dot-dashed curve).

Figure 3-3 Roughness value $(\mathrm{m})$ by compass sector surrounding the N-Area tower computed from the three measurements of turbulence intensities: $\sigma_{u}$, (with $\mathrm{U}>5.0 \mathrm{~m} / \mathrm{s}$; magenta, solid curve), $\sigma_{A}$ (red, dashed curve) and $\sigma_{E}$ (green, dot-dashed curve).

Figure 4-1 USGS Land Cover Data for SRS used by EPA's AERSURFACE Algorithm. 


\section{LIST OF ABBREVIATIONS}

$\begin{array}{ll}\text { SRNL } & \text { Savannah River National Laboratory } \\ \text { SRS } & \text { Savannah River Site } \\ \text { EPA } & \text { Environmental Protection Agency } \\ \text { NLCD } & \text { National Land Cover Data }\end{array}$




\subsection{Introduction}

Roughness length $\left(z_{o}\right)$ is a parameter that accounts for irregularities in the surface which, in turn, affects the change of wind speed with height in the atmospheric boundary layer. Roughness also affects atmospheric plume dispersion downwind of both surface and elevated releases. Specifically, the MELCOR Accident Consequence Code System, Ver. 2 (MACCS2) model, that includes a Gaussian dispersion model for design basis accident dose calculations at SRS, adjusts the vertical dispersion coefficient $\sigma_{\mathrm{z}}$ based on input of a site-specific roughness.

Determining roughness for potential pollutant releases at the Savannah River Site (SRS) must be carefully considered. In former operations areas, tall trees, shrubs and other vegetation have been replaced with grass, one or two-story buildings and reactor or separations buildings containing several floors. Also, as a dispersing plume moves downwind through the SRS, it rapidly exits the clearings and production areas and encounters mostly forested terrain until it reaches the site boundary. At the boundary, roughness elements change to agricultural and mixed pine/hardwood forest, including low crops, scattered shrubs, tree farms, etc. After leaving the southern site boundary, a dispersing plume would encounter the Savannah River channel and associated wetland environments. The land characterization outside the remaining plant boundaries includes farming, with low crops or tree farms, small towns, etc.

With several operations areas of potential interest (A, B, C, D, F, H, N, etc.) and sixteen wind direction sectors ( $\mathrm{N}, \mathrm{NNE}, \mathrm{NE}, \mathrm{ENE}, \mathrm{E}$, etc.) there are many combinations that need to be considered for a potential release. For forested areas across the SRS, this report will concentrate on roughness near H-Area meteorological tower, which is particularly important as the primary source of meteorological data used in regulatory compliance modeling at SRS. Furthermore, the area around the H-area tower has the most extensive and uniform tree canopy of the SRS towers and, based on high-resolution canopy height data collected by the U.S. Forest Service at SRS, provides results that are generally representative of the forested areas throughout the SRS. Roughness estimates for the operations areas are calculated separately using the Environmental Protection Agency's (EPA) computer algorithm AERSURFACE.

\subsection{Procedure}

Roughness length and displacement height

As mentioned above, roughness is a parameter in atmospheric surface layer wind descriptions that accounts for the irregularities in ground, water, ice, or other surfaces over which air moves. For simple surfaces such as uniform grass, the roughness represents an effective height at which the wind speed becomes zero. Roughness arises when calculating the change of wind speed with height in the atmospheric boundary layer. Using the Monin-Obukhov similarity theory for the atmospheric surface layer, the diabatic wind law is

$U(z)=\left(u_{*} / k\right)\left\{\ln \left[(z-d) / z_{0}\right]-\Psi\left[(z-d) / L, z_{0} / L\right]\right\}$

where $U$ is the wind speed, $z$ is the height above the surface, $u_{*}$ is the friction velocity, $k$ is the Von Karman constant, $d$ is the displacement height, $z_{0}$ is the roughness, $\Psi$ is the stability correction function and $L$ is the Monin-Obukhov length (Panofsky and Dutton, 1984). Solving for the roughness in terms of the other parameters and the stability correction function we find 


$$
z_{0}=(z-d) \exp \left\{-k U / u_{*}-\Psi\left[(z-d) / L, z_{0} / L\right]\right\}
$$

The wind law (Eq.1) describes the wind speed change with height when local equilibrium conditions exist. Local equilibrium is generally perceived to mean that there is a balance between turbulence production and dissipation (Martano, 2000). These conditions can occur over homogeneous terrain when the ratio between uniform horizontal fetch and measurement height is large enough to allow equilibrium to be reached (Panofsky and Dutton, 1984). Fetch represents an upwind area that influences the characteristics of the wind measured at a given location. The upwind fetch distance increases with increasing measurement height and is also influenced by $U$, $u_{*}$ and $z_{0}$.

When the sensible heat flux is zero (i.e., neutral stability), Eq. 1 reduces to a much simpler form containing only $u_{*}, z_{0}$ and $\mathrm{d}$. Thus, one needs only to measure wind speed and measure or calculate friction velocity at two elevations to evaluate the displacement height and roughness from,

$z_{0}=(z-d) \exp \left\{-k U / u_{*}\right\}$

Even when two measurement levels are available, it is essential that the upwind terrain is uniform, otherwise internal boundary layers will develop and invalidate the assumptions in the logarithmic wind law. Within SRS, there are only two wind towers where two or more levels of wind speed are available, D-Area and N-Area. Since H-Area has only one measurement height and the normally available meteorological instruments (bivanes and cup anemometers) cannot measure friction velocity directly, the problem of roughness determination is more difficult. To solve this problem, additional methods or measurements are used.

The displacement height is a parameter in the wind law that is needed when wind flows through a canopy such as shrubs or forest. The displacement height defines a new horizontal surface above the ground where wind speed becomes nearly zero, i.e., at $z=d+z_{0}$. Normally, the displacement height has been found to be a factor of 0.6-0.8 of the height of the large roughness elements (Panofsky and Dutton, 1984). Roughness values vary from about $3 \mathrm{~cm}$ over cut grass surfaces to a few meters in cities with tall buildings. Displacement height is typically an order of magnitude greater than roughness.

\section{$\underline{\text { Simple estimations of roughness and displacement height }}$}

Published tables with terrain descriptions and corresponding roughness estimates have been used in the past (Randerson, 1984; Panofsky and Dutton, 1984; Royal Aeronautical Society, 1972; EPA, 2000). However, these tables give a wide range of roughness for similar terrain. For the forested terrain over the majority of the SRS, these tables indicate a roughness length ranging from a fraction of a meter to about 3 meters.

Over the past several decades, investigators have sought to provide roughness estimates based on the height of the underlying vegetation, sometimes considering leaf area index and/or average tree geometry. Recently, Crockford and Hui (2007) tested and evaluated simple methods of estimating roughness and displacement height in forested terrain using only simple formulas that require a few parameters describing the tree canopy. Two of their recommended models for roughness are 
$z_{0}=0.075 h$

and

$z_{0}=(h-d) \exp \left[-k\left(U_{h} / u_{*}\right)+\Psi_{h}\right]$

where h is the tree canopy height, $d$ is displacement height, $U_{h} / u_{*}$ is an inverse drag coefficient and $\Psi_{h}$ is a roughness sublayer influence function (Raupach, 1994). The first method (Eq. 4) is from Hicks et al. (1975) and Jarvis (documented in Irvine et al., 1997). The inverse drag coefficient and $\Psi_{h}$ can be simplified further in terms of tree frontal area index, which can be calculated knowing tree height, breadth and spacing.

Crockford and Hui (2007) recommended four formulas for displacement height: two simple formulas requiring only canopy height and another two requiring leaf area index or frontal area index. We chose to use Crockford and Hui's first simple formula requiring only canopy height to calculate the displacement height as follows:

$d=0.75 h$

which is from Garratt (1992) and also Dolman (documented in Baldocchi and Meyers, 1988). Crockford and Hui (2007) found that Eq. 6 resulted in an accurate estimate of $d$ for forested terrain when compared with values determined using measurements from cup and sonic anemometers.

\section{$\underline{\text { Roughness determination requiring meteorological measurements }}$}

More theoretically based methods of determining roughness require meteorological measurements and can be used when the data is available. Some frequently used methods rely on simplifications that can be made to the wind law when the atmospheric surface layer is neutrally stable. In this case, similarity theory requires simple relations between $u_{*}$ and $\sigma_{u}, \sigma_{v}$ or $\sigma_{w}$, the standard deviations of the lateral, longitudinal and vertical wind velocity components

$\sigma_{u}=A u_{*}$

$\sigma_{v}=B u_{*}$

$\sigma_{w}=C u_{*}$

where A, B and C are constants that have been determined to be 2.5, 1.9 and 1.25 (Panofsky and Dutton, 1984; Arya, 2001; and Bowen, 2008).

The first equation above is perhaps the simplest to use because it requires only $\sigma_{u}$, an estimate of wind gustiness, available from a standard anemometer. Additionally, assuming the required data are available, the standard deviation of the wind's horizontal or vertical angle ( $\sigma_{A}$ or $\sigma_{E}$ ) can be used together with simple approximations to determine the friction velocity. 
and

$$
\sigma_{w} \cong U \sigma_{E}
$$

These approximations and their accuracy are discussed by Slade (1968), Panofsky and Dutton (1984) and Weber, et al. (1975). When displacement height and friction velocity are known it is possible to determine roughness values using archived 15-minute averaged SRNL tower data.

$z_{0}=(z-d) \exp \left\{-U / \sigma_{U}\right\}$

(requires $\mathrm{U}$, wind gustiness and $\mathrm{d}$ )

$z_{0}=(z-d) \exp \left\{-0.76 / \sigma_{A}\right\}$

(requires $\sigma_{A}$ and d)

$z_{0}=(z-d) \exp \left\{-1 / 2 \sigma_{E}\right\}$

(requires $\sigma_{E}$ and d)

The EPA (2000) mentions the first of these three equations for determining roughness, knowing that most locations are more likely to have $\sigma_{u}$ data rather than vertical and lateral wind turbulence intensity components. However, some studies have noted that use of $\sigma_{u}$, rather than $\sigma_{E}$ yields a roughness value biased by the effects of upwind terrain changes and obstacles over many kilometers (Tielman, 1992, and Bowen, 2008). Conversely, roughness based on vertical turbulence intensity is more likely to reflect a more relevant local roughness for the surrounding vegetation.

Further caveats on using the horizontal turbulence scaling relations have been emphasized by B.B. Hicks and summarized in Andreas and Hicks (2002) when they stated that -- Perhaps it is time to acknowledge that the horizontal velocity variances $\sigma_{u}^{2}, \sigma_{v}^{2}$, ... violate too many of the assumptions on which Monin-Obukhov similarity relies and to stop trying to force them into artificial similarity relations. In all but, maybe, the strongest winds, large eddies dictate the behavior of these variances. But these eddies reflect mesoscale variations in clouds, vegetation, surface slope, soil moisture, and the height of the boundary layer, among other parameters, and therefore cannot be in equilibrium with the local surface. Consequently, the largest eddies almost always violate the assumption of horizontal homogeneity that Monin-Obukhov similarity requires. Fortunately, as can be seen from Eqs. 12, 13, and 14, small errors in estimating displacement height are not too serious in determining roughness, since the roughness is directly proportional to the difference between instrument and displacement height $(z-d)$, provided all other parameters in the equations are known quite accurately. Thus a $10-15 \%$ error in $(\mathrm{z}-d)$ will produce a $10-15 \%$ error in the expected roughness.

\section{The flux footprint and fetch}

The upwind fetch and the flux footprint are related concepts. The flux footprint is the relative contribution to the measured fluxes of momentum from each upstream surface point. The footprint depends on the friction velocity $\boldsymbol{u}_{*}$ (momentum flux), the wind direction and wind 
speed, the atmospheric stability and the measurement height. If a spatially homogeneous landscape is assumed, i.e., a single value for $\boldsymbol{u}_{*}$, the flux footprint $F$ can be found following methods by Soegaard et al. (2003).

$$
\begin{aligned}
& F_{x, y}=\frac{F_{x}}{\sqrt{2 \pi} \sigma_{y}} \exp \left\{-y^{2} / 2 \sigma_{y}^{2}\right\} \\
& F_{x}=\frac{U z_{m}}{u_{*} k x^{2}} \exp \left\{-U z_{m} / k u_{*} x\right\}
\end{aligned}
$$

In Eqs. (15 \& 16), $U, z_{m}, \boldsymbol{u}_{*}$, and $k$ are the mean wind speed, measurement height, friction velocity, and von Karman constant (0.4), respectively. The towers were assumed to be $43 \mathrm{~m}$ above the displacement height of $18 \mathrm{~m}$ in all three cases (measurement height - displacement height). The cross-stream dependence $\sigma_{\mathrm{y}}$ given in Eq. (15) is based on Gaussian diffusion. Values of $\sigma_{\mathrm{y}}$ were calculated from dispersion coefficients given by Briggs (1973). The Briggs data are based on actual measurements and should be more reliable than the estimates given in Appendix A of Soegaard et al. (2003). Eqs. (15 \& 16) assume uniform terrain and roughness length, which is a good assumption for H-Area but not for some quadrants at the Climatology and D-Area towers. The expression could be applied to complex landscapes if a suitable average $\boldsymbol{u}_{*}$ can be found. The footprints should be approximately correct even for complex terrain, but a rigorous treatment of upwind variability is much more complicated.

Figures 2-1 through 2-3 show flux footprints for $\mathrm{H}, \mathrm{D}$ and N-Area measurements, respectively, based on a typical $U(5 \mathrm{~m} / \mathrm{s})$ and $u_{*}(0.5 \mathrm{~m} / \mathrm{s})$ during neutral conditions. Under these conditions, the upwind fetch distance for mechanically generated turbulence at the H-Area tower is between 0.20-1.2 km for the 61-m level. The width of the largest fetch-influence isopleth for H-Area is approximately $140 \mathrm{~m}$. (The three isopleths denote contributions to the flux equal to $0.25,0.5$, and 0.75 times the maximum value, i.e., the center-point within the smallest contour.) We estimate that $\sim 75 \%$ of the flux originates from within the contour with the largest area.

The flux footprint shows how much of the measured flux originates from forest and how much is 'contaminated' by industrial areas. In these examples, fluxes measured at the H-Area are mostly uncontaminated while those from the D-Area and N-Area towers originate in part from industrial surfaces. 


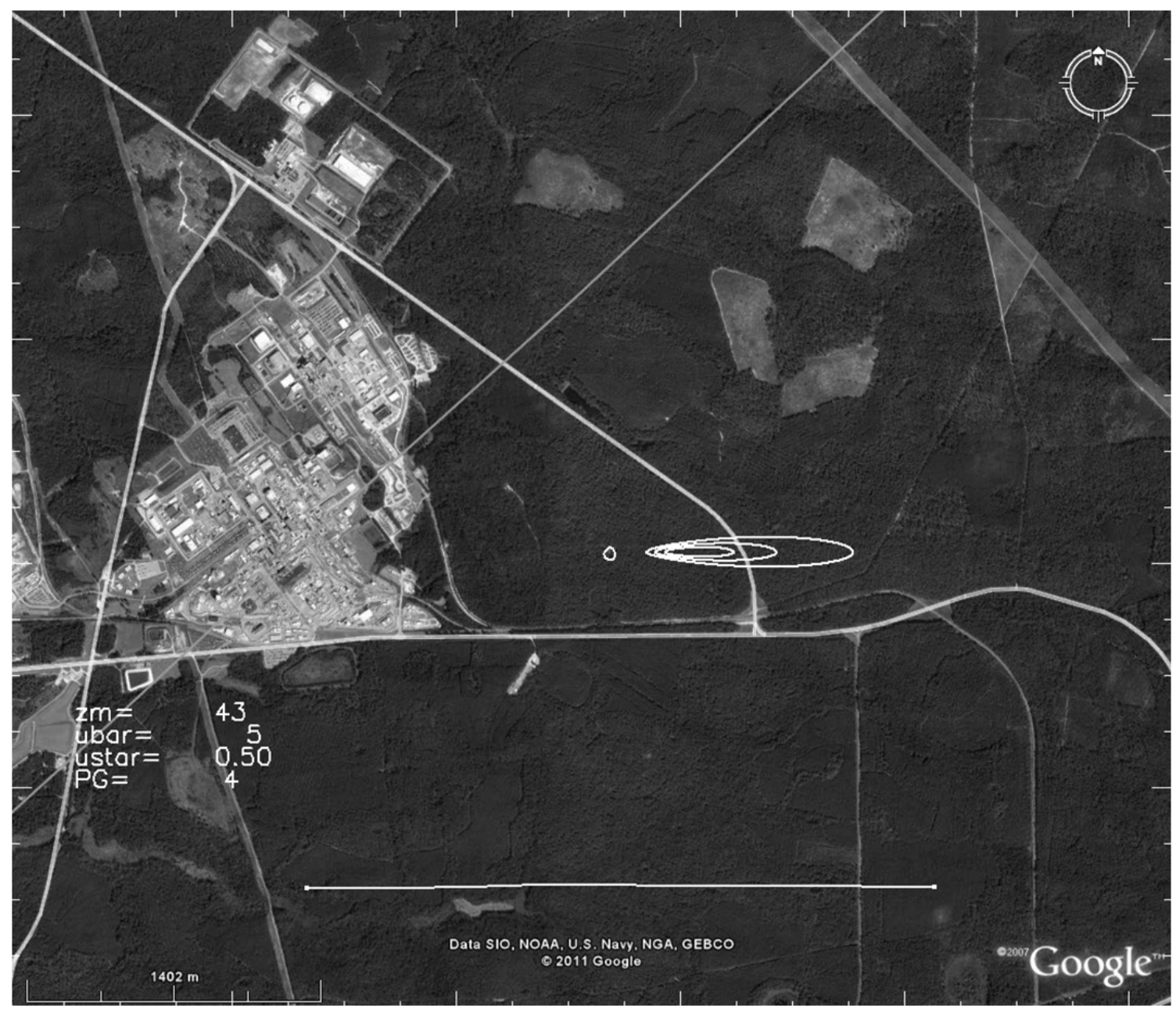

Figure 2-1. Sample $H$-Area fetch for an east wind showing areas of most influence for a 43$\mathrm{m}$ height, $5 \mathrm{~m} / \mathrm{s}$ wind speed, $0.50 \mathrm{~m} / \mathrm{s}$ friction velocity and neutral stability (Class D). The horizontal line in the figure is $3 \mathrm{~km}$. The $43-\mathrm{m}$ height $\left(\mathrm{z}_{\mathrm{m}}\right)$ represents the height of the $\mathrm{H}$ Area tower measurement relative to an 18-m displacement height. 


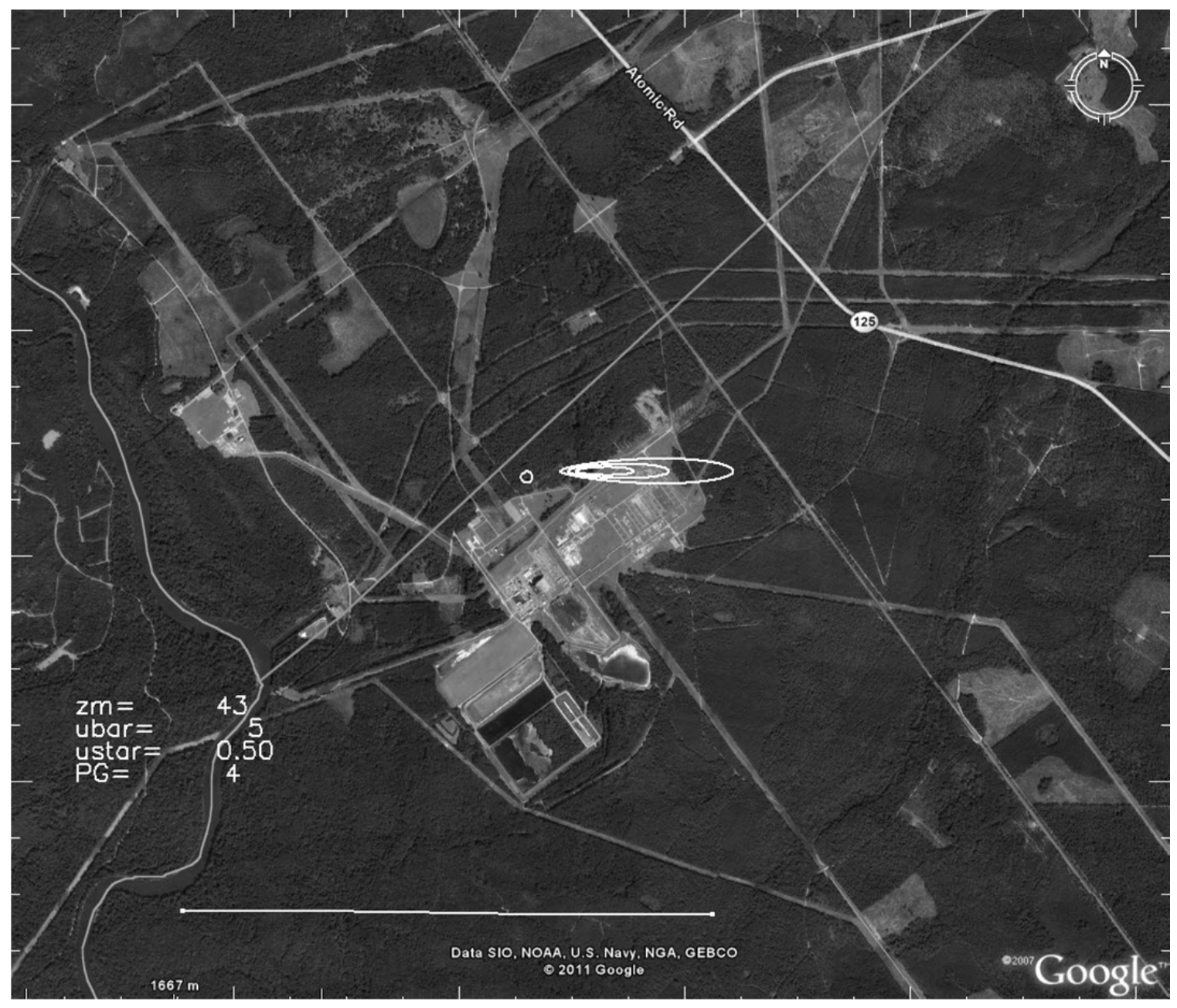

Figure 2-2. Sample D-Area fetch for an easterly wind showing areas of most influence for a 43- $\mathrm{m}$ height, $5 \mathrm{~m} / \mathrm{s}$ wind speed, $0.50 \mathrm{~m} / \mathrm{s}$ friction velocity and neutral stability (Class D). The horizontal line in the figure is $3 \mathrm{~km}$. The $43-\mathrm{m}$ height $\left(\mathrm{z}_{\mathrm{m}}\right)$ represents the height of the $D$ Area tower measurement relative to an 18-m displacement height. 


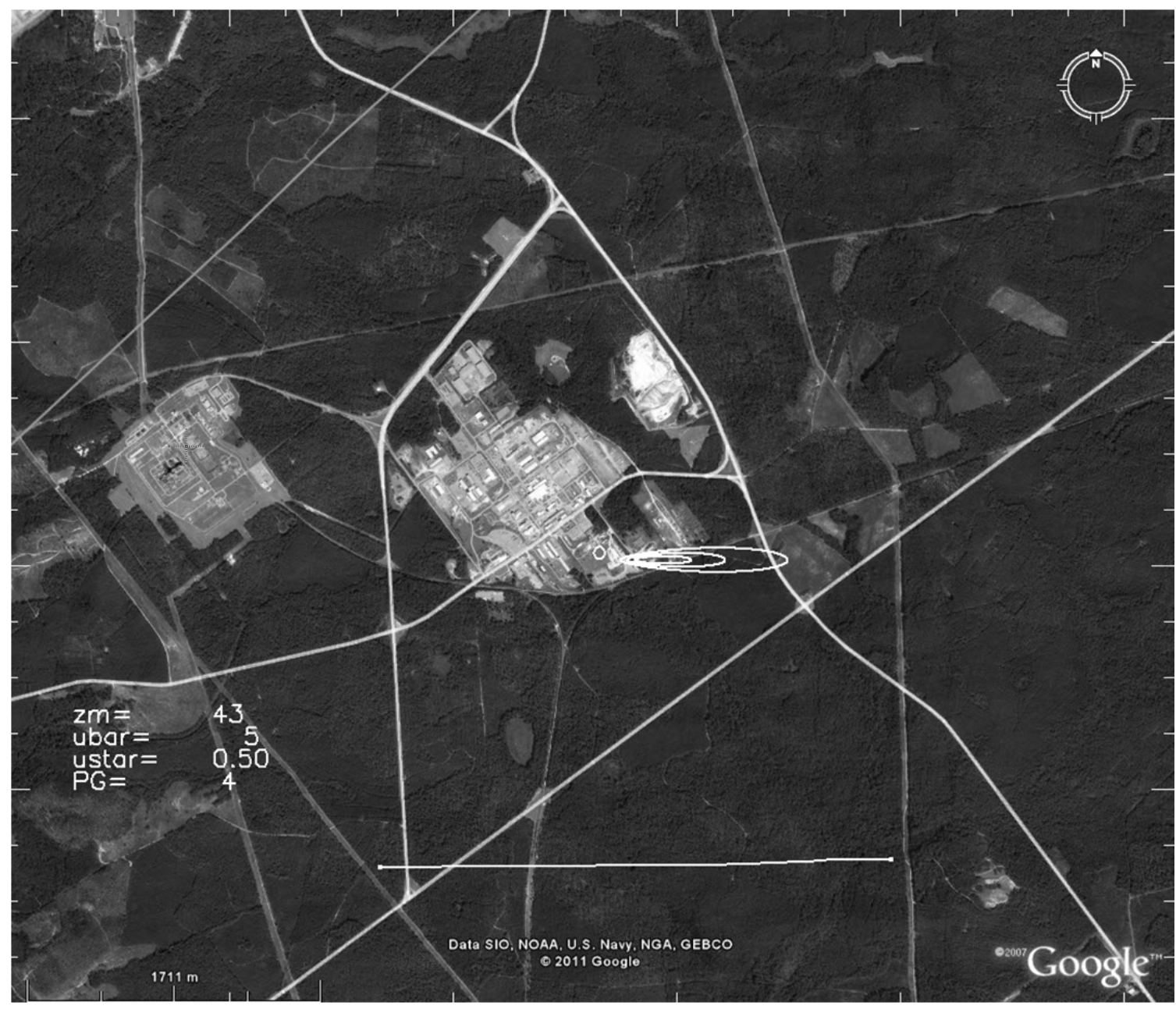

Figure 2-3. Sample N-Area fetch for an easterly wind showing areas of most influence for a 43-m height, $5 \mathrm{~m} / \mathrm{s}$ wind speed, $0.50 \mathrm{~m} / \mathrm{s}$ friction velocity and neutral stability (Class D). The horizontal line in the figure is $3 \mathrm{~km}$. The $43-\mathrm{m}$ height $\left(\mathrm{z}_{\mathrm{m}}\right)$ represents the height of the $N$ Area tower measurement relative to an 18-m displacement height.

\subsection{Results and Discussion}

\section{Displacement height and roughness from simple estimations}

Displacement height for the forest canopy surrounding the H-area tower was determined using canopy height data provided by the U. S. Forest Service (USFS) at Savannah River (Kabela, 2011). The canopy data were collected in 2009 using an aircraft-based lidar (McGaughey and Reutebuck, 2009) providing $2 \mathrm{~m}$ resolution data. The data provided by USFS consisted of average, $90^{\text {th }}$ percent, and $95^{\text {th }}$ percent canopy height for an area within a $2000-\mathrm{ft}$ radius of the $\mathrm{H}$-area tower. The resulting values are $21 \mathrm{~m}, 23 \mathrm{~m}$, and $24 \mathrm{~m}$ respectively. The 95th percent value of 24 $\mathrm{m}$ was used in this analysis, giving a displacement height of $18 \mathrm{~m}$ using Eq. 6 and a roughness length of $1.8 \mathrm{~m}$ from Eq. 4. As indicated by Eqs. (12-14), higher values of displacement height will yield lower estimates of roughness; therefore, the use of the $95^{\text {th }}$ percent canopy height data is conservative with respect to the parameterization of enhanced vertical diffusion used in the MACCS2 model. 
SRNL-STI-2012-00016

Revision 0

\section{$\underline{\text { Determination of stability category and turbulence correction factors }}$}

The EPA has developed a set of guidelines for regulatory modeling applications (EPA, 2000). Within the EPA guidelines are recommended methods for establishing stability categories depending on instrumentation available at a given site with provisions for using $\sigma_{E}$ or $\sigma_{A}$. The EPA provides recommended ranges of $\sigma_{E}$ or $\sigma_{A}$ for neutral conditions that are needed in this work to determine roughness values using Eqs. (12-14). The EPA method first establishes a base range for $\sigma_{E}$ or $\sigma_{A}$ which is then modified for sites with roughness values different from 15 $\mathrm{cm}$, and measurement heights that differ from $10 \mathrm{~m}$. Neutral conditions were selected according to the EPA (2000) method using the base values followed by the two corrections. Corrections were applied to neutral (Class D) limits for both $\sigma_{E}$ and $\sigma_{A}$. The first correction was applied to $\sigma_{E}$ and $\sigma_{A}$ in order to account for sites where the roughness is different from $15 \mathrm{~cm}$.

The correction factor for roughness length is $\left(z_{0} / 15\right)^{0.2}$. Since the simple roughness estimate from the preceding section (Eq. 4) is $1.8 \mathrm{~m}$ (and a preliminary measurement-based roughness value is also shown to be around $1.8 \mathrm{~m}$ ) the calculated roughness correction factor is 1.644. This correction factor reflects the fact that a tree canopy will require a larger value of $\sigma_{E}$ and $\sigma_{A}$ to qualify as 'neutral' than a site with the default parameters (Irwin, 1980).

The second correction was applied to allow for a measurement height $(z-d)$ other than $10-\mathrm{m}$. A separate correction factor is needed for $\sigma_{E}$ and $\sigma_{A}$. In neutral conditions, the height correction for the lower bound of the $\mathrm{D}$ range for $\sigma_{E}$ is $((z-d) / 10)^{-0.14}$ and for $\sigma_{A}$ is $((z-d) / 10)^{-0.23}$. Using an $\mathrm{H}-$ Area $z$ of $61 \mathrm{~m}$ and a $d$ of $18 \mathrm{~m}$, this correction factor reduces the standard deviation of the vertical wind direction needed for the lower bound of the $\mathrm{D}$ range for $\sigma_{E}$ and $\sigma_{A}$ by 0.815 and 0.715 , respectively. The roughness correction works in the opposite sense from the height correction. The net changes in the limits for neutral $\sigma_{E}$ and $\sigma_{A}$ are 1.34 and 1.18 for the bottom of the D category, and 1.67 and 1.28 for the bottom of the $\mathrm{C}$ category, respectively, which result in the ranges $\left(6.70<=\sigma_{E}<=13.00\right)$ and $\left(8.81<=\sigma_{A}<=16.03\right)$ for neutral stability. (See Appendix A for more details.)

\section{Data selection from the SRNL archives}

SRNL collects 15-min averages of meteorological measurements from bivanes and cup anemometers from nine locations across SRS. These 15-min averages are quality checked and maintained in a computer database that includes wind speed and direction (both horizontal and vertical) and their standard deviations, temperature and humidity measurements (Parker and Addis, 1993). These measurements are reviewed daily and annually and an appropriate quality code is assigned to each record. Data for 2010 for the H-Area tower with a "G" quality code (implying that the data passed initial quality checks) were chosen for this study.

The data were grouped into compass sectors listed in Table 3-1 based on the average 61-m wind direction $(\theta)$ at $\mathrm{H}$-Area. 
Table 3-1. Wind direction sector designations with lower and upper bounds for wind direction (proceeding clockwise). Wind direction is the direction from which the wind is blowing.

\begin{tabular}{|c|c|c|}
\hline Sector designation & $\begin{array}{c}\text { Lower bound } \\
\text { wind direction }\end{array}$ & $\begin{array}{c}\text { Upper bound } \\
\text { wind direction }\end{array}$ \\
\hline 01_N & 348.75 & 11.25 \\
\hline 02NNE & 11.25 & 33.75 \\
\hline 03_NE & 33.75 & 56.25 \\
\hline 04ENE & 56.25 & 78.75 \\
\hline 05_E & 78.75 & 101.25 \\
\hline 06ESE & 101.25 & 123.75 \\
\hline 07_SE & 123.75 & 146.25 \\
\hline 08SSE & 146.25 & 168.75 \\
\hline 09_S & 168.75 & 191.25 \\
\hline 10SSW & 191.25 & 213.75 \\
\hline 11_SW & 213.75 & 236.25 \\
\hline 12WSW & 236.25 & 258.75 \\
\hline 13_WW & 258.75 & 281.25 \\
\hline 14WNW & 281.25 & 303.75 \\
\hline 15_NW & 303.75 & 326.25 \\
\hline 16NNW & 326.25 & 348.75 \\
\hline
\end{tabular}

Restrictions on $\sigma_{\mathrm{A}}, \sigma_{\mathrm{E}}$ and wind speed during each 15-min period to ensure neutral conditions were as follows:

$$
\left(6.70<=\sigma_{E}<=13.01\right) \&\left(8.81<=\sigma_{A}<=16.03 \text {, degrees }\right) \&(2.0<=U<=13.0, \mathrm{~m} / \mathrm{s})
$$

except for the method based on $\sigma_{u}$, which required (5.0 $<=U<=13.0$ ), following the EPA (2000) guidelines. The restriction on wind speed (i.e., $2.0<=U<=13.0, \mathrm{~m} / \mathrm{s}$ ) is based on the authors' attempt to ensure adequate wind speed above the bivane threshold, but not so strong a wind as to include storm conditions.

Roughness calculations based on vertical and horizontal turbulence intensities and wind speed gustiness

Once displacement height is estimated adequately, and neutral conditions established by limiting the ranges of $\sigma_{E}$ and $\sigma_{A}$, then tower measurements can be used to estimate roughness based on Eqs (12-14). The results are shown in Figs. 3-1 through 3-3 and Tables 3-2 and 3-3. The results for the north sector are omitted due to an occasional anomaly in output from the bivane for a small gap of a few degrees of wind direction within this sector. Since terrain and vegetation cover surrounding the $\mathrm{H}$-area tower is generally uniform in all directions within the fetch area (see Fig. 2-1), omission of the north sector data will have no significant effect on the overall results. 


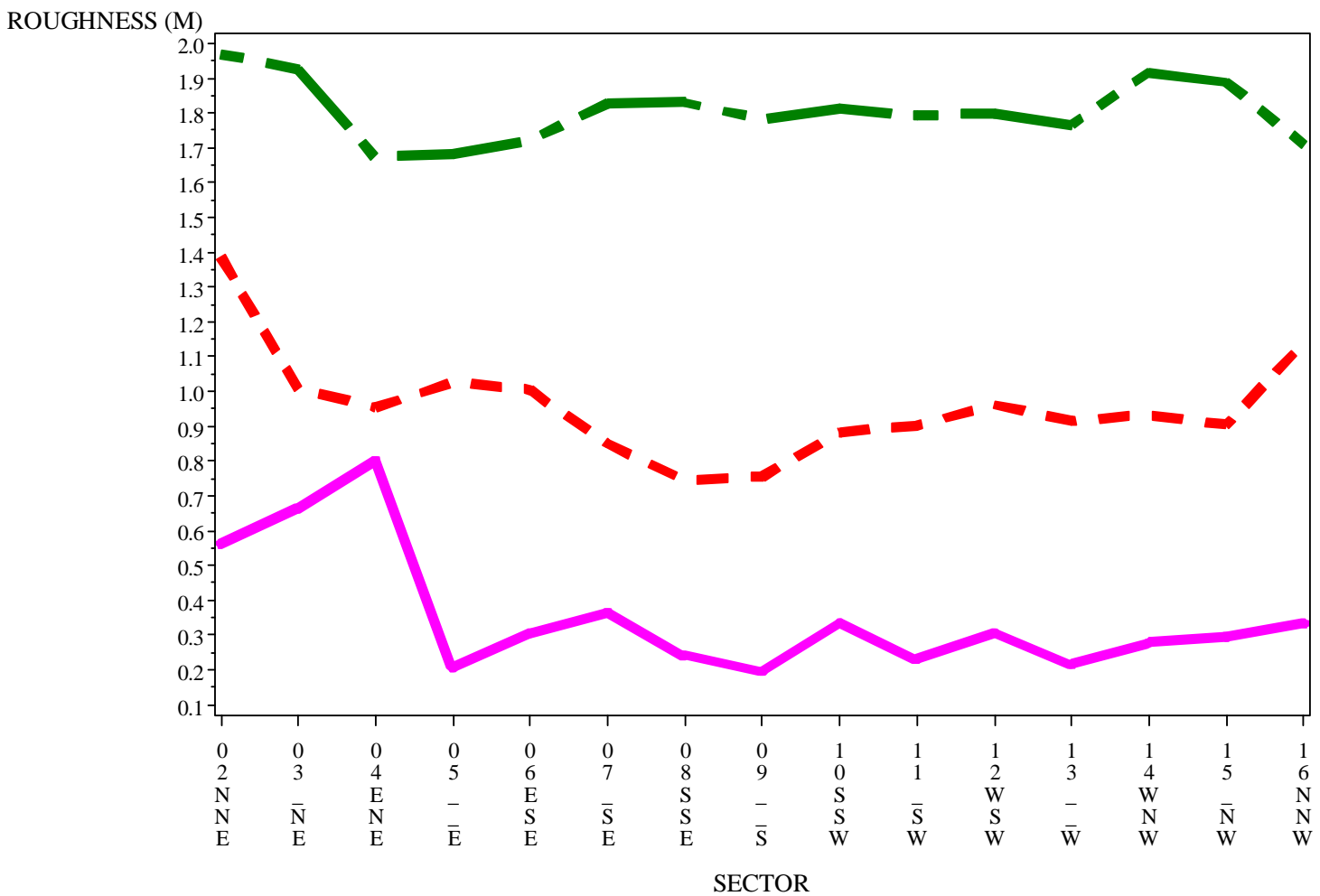

Figure 3-1. Roughness value $(\mathrm{m})$ by compass sector surrounding the H-Area tower computed from the three measurements of turbulence intensities: $\sigma_{u}$, (with $U>5.0 \mathrm{~m} / \mathrm{s}$; magenta, solid curve), $\sigma_{A}$ (red, dashed curve) and $\sigma_{E}$ (green, dot-dashed curve). 


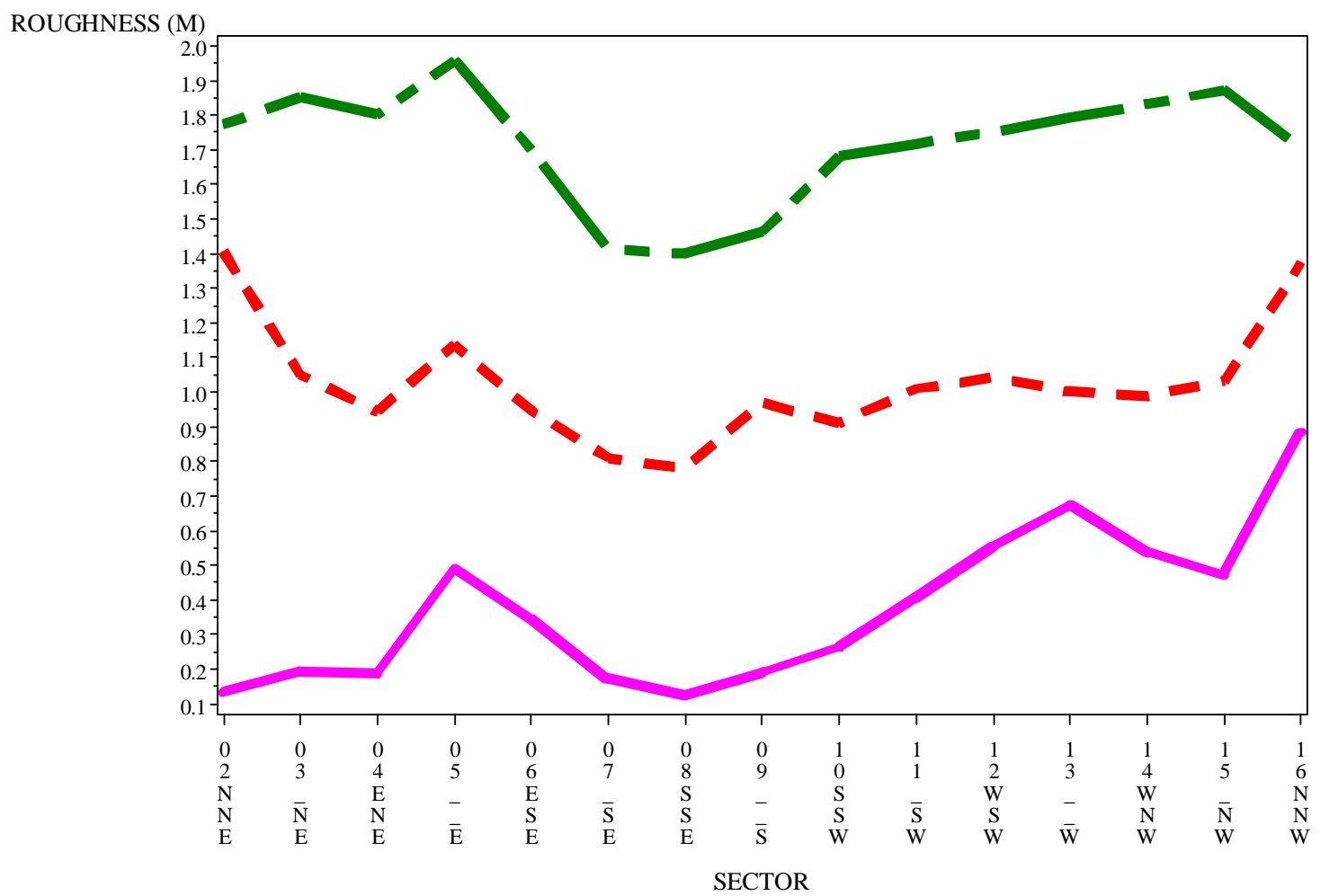

Figure 3-2. Roughness value $(\mathrm{m})$ by compass sectors surrounding the D-Area tower computed from the three measurements of turbulence intensities: $\sigma_{u}$, (with $U>5.0 \mathrm{~m} / \mathrm{s}$; magenta, solid curve), $\sigma_{A}$ (red, dashed curve) and $\sigma_{E}$ (green dot-dashed curve). 


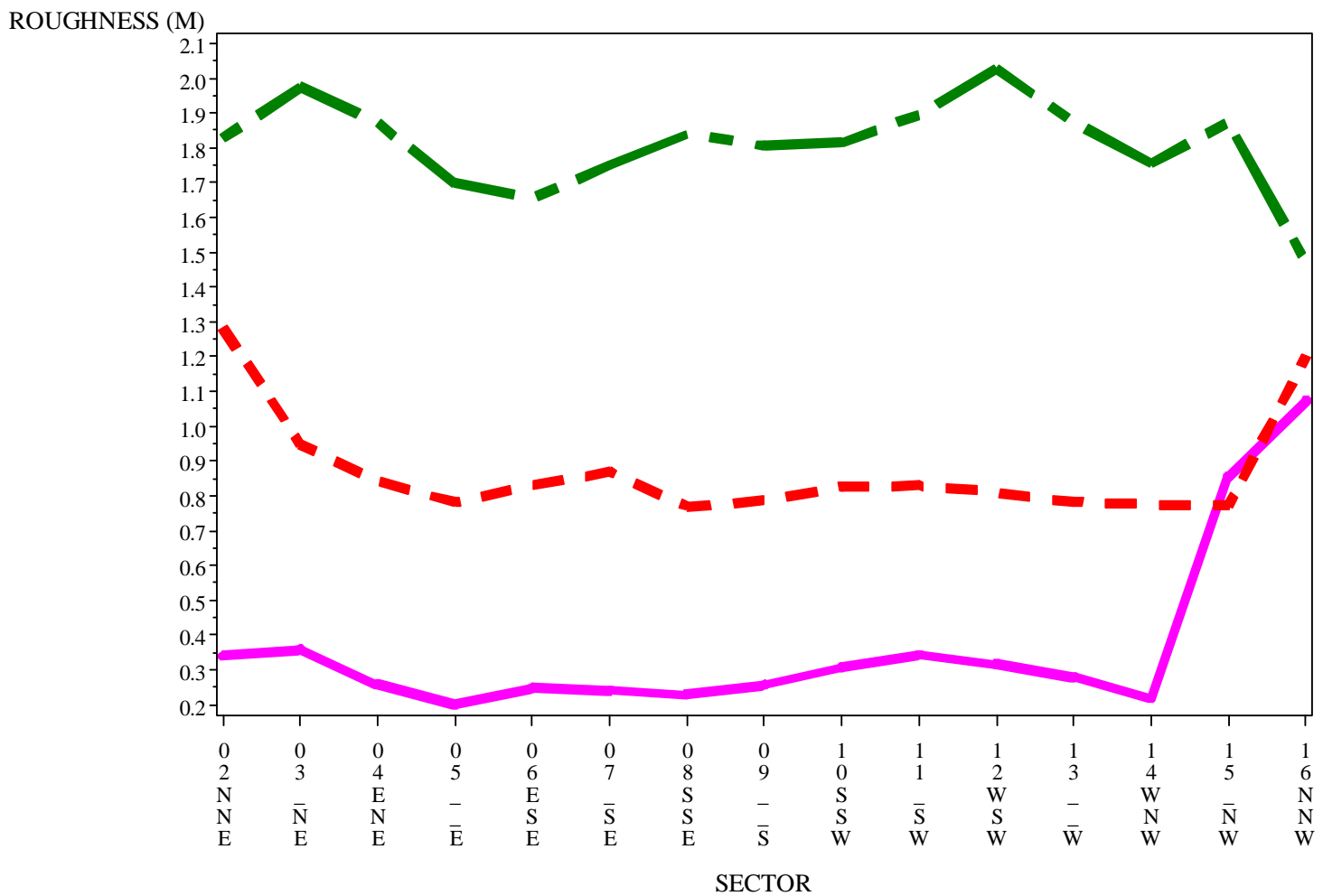

Figure 3-3. Roughness value $(\mathrm{m})$ by compass sectors surrounding the N-Area tower computed from the three measurements of turbulence intensities: $\sigma_{u}$, (with $U>5.0 \mathrm{~m} / \mathrm{s}$; magenta, solid curve), $\sigma_{A}$ (red, dashed curve) and $\sigma_{E}$ (green, dot-dashed curve).

The direct application of the formulas for roughness distribution tends to contain outliers, since the calculation is the result of an exponential function raised to the ratio of measured values. To limit outliers, we rejected data for which the calculated roughness was greater than $3 \mathrm{~m}$, a value that was believed to be too large for the vegetation within SRS. An additional measure to ensure reasonable results was to use mean values of the parameters $U, \sigma_{A}, \sigma_{E}$ and $\sigma_{u}$ in Eqs. (12-14). The mean values of roughness for each method are generally uniform with compass sector (Table 3-2), and the overall variances (i.e., 95\% confidence limits) are relatively small (Table 3-3), particularly for the H-Area tower where the entire fetch encompasses a relatively uniform forest. The average over the 15 sectors for H-Area is $1.81 \mathrm{~m}$ based on the $\sigma_{E}$ method, $0.96 \mathrm{~m}$ based on the $\sigma_{A}$ method and $0.36 \mathrm{~m}$ based on the $\sigma_{u}$ method. The average over the 15 sectors for D-Area is $1.71 \mathrm{~m}$ based on the $\sigma_{E}$ method, $1.03 \mathrm{~m}$ based on the $\sigma_{A}$ method and $0.38 \mathrm{~m}$ based on the $\sigma_{u}$ method. The average over the 15 sectors for $\mathrm{N}$-Area is $1.81 \mathrm{~m}$ based on the $\sigma_{E}$ method, $0.87 \mathrm{~m}$ based on the $\sigma_{A}$ method and $0.37 \mathrm{~m}$ based on the $\sigma_{u}$ method. 
SRNL-STI-2012-00016

Revision 0

Table 3-2. Averaged roughness length over 15 wind direction sectors based on measurements from the $\mathrm{H}$-Area tower, $\mathrm{D}$-Area tower, and $\mathrm{N}$-Area tower bivane and cup anemometers.

\begin{tabular}{|c|c|c|c|}
\hline & $\begin{array}{c}\text { Roughness } \\
\text { based on } \\
\sigma_{u} \text { and } U \text { method }\end{array}$ & $\begin{array}{c}\text { Roughness } \\
\text { based on } \\
\sigma_{A} \text { method }\end{array}$ & $\begin{array}{c}\text { Roughness } \\
\text { based on } \\
\sigma_{E} \text { method }\end{array}$ \\
\hline $\mathrm{D}$ & 0.38 & 1.03 & 1.71 \\
\hline $\mathrm{N}$ & 0.37 & 0.87 & 1.81 \\
\hline $\mathrm{H}$ & 0.36 & 0.96 & 1.81 \\
\hline
\end{tabular}

Table 3-3. Roughness mean, lower (95\%) confidence interval of the mean and upper (95\%) confidence interval of the mean for neutral cases, for 15 compass sectors using $\sigma_{E}$ measurements from the 61-m level of each tower (H-Area, D-Area and N-Area).

\begin{tabular}{|c|c|c|c|}
\hline Area & Mean roughness & LCLM (95\%) & UCLM (95\%) \\
\hline $\mathrm{H}$ & 1.81 & 1.76 & 1.86 \\
\hline $\mathrm{D}$ & 1.71 & 1.62 & 1.81 \\
\hline $\mathrm{N}$ & 1.81 & 1.73 & 1.88 \\
\hline
\end{tabular}

$\underline{\text { Recommendation of the } \sigma_{E}}$ method

The roughness calculations based on the $\sigma_{E}$ method are recommended as the preferred estimate of roughness. Crockford and Hui's (2007) results based on a simple formula involving mean canopy height were given a major weight in this decision since their study was comprehensive, involving the testing of several possible combinations of roughness and displacement height formulae in forested terrain using meteorological masts instrumented with both cup and sonic anemometers.

Roughness calculations based on the 15-minute averages of $\sigma_{A}$ and $\sigma_{u}$ are felt to be strongly biased downward in this study since they do not agree with each other or the calculations based on $\sigma_{E}$. In the past, the use of $\sigma_{u}$ to compute roughness has been discouraged because it reflects large-scale roughness features far upstream that are slow to decay (Tielman, 1992; Bowen, 2008). Beljaars (1987) also emphasized that " $\sigma_{u}$ and $\sigma_{v}$ show slow relaxation (response) to the local surface conditions in complex terrain".

Another factor that may cause smaller roughness values from the $\sigma_{A}$ and $\sigma_{u}$ methods is that the 15-minute averaging time for these quantities may not capture the full spectrum of relevant turbulence scales, which decreases the value of roughness they predict. Even if a one-hour average of either $\sigma_{A}$ and $\sigma_{u}$ were used, it would include changes in mean values of wind direction and speed between each 15-min period. The result is that when mean wind directions are changing during a 1-hr period (as they almost always do) the combined variances values for the 1-hr period are larger (since they include terms for the changes in mean wind direction from one 
15-min period to another). The $\sigma_{E}$ method does not have this disadvantage since the mean value of the vertical angle of wind is almost always close to zero.

Finally, sonic anemometer measurements from the H-Area meteorological tower during several weeks in early 2010 were used as a confirmation of our calculations using bivane data. These measurements were not taken with the specific intent of determining roughness but the existence of this data enabled direct computation of friction velocity, wind speed and sensible heat flux. Therefore, neutral stability cases could be selected to determine roughness from direct application of Eq. (3) with displacement height estimated using the same method as used earlier in this report (Table 3-4). Thirty cases of neutral stability near sunrise or sunset with sensible heat flux close to zero were used for this determination.

Table 3-4. Roughness mean, lower (95\%) confidence interval of the mean and upper $(95 \%)$ confidence interval of the mean for neutral cases, selected from sonic anemometer-deriveddata from the 61-m level at H-Area.

\begin{tabular}{|c|c|c|c|}
\hline Area & Mean roughness & LCLM (95\%) & UCLM (95\%) \\
\hline $\mathrm{H}$ & 1.54 & 1.26 & 1.83 \\
\hline
\end{tabular}

These results are in closer agreement with the roughness computed using $\sigma_{E}$ and are close to the simple canopy height methods used by Crockford and Hui (2007). Sonic anemometer results following the EPA methods for using $\sigma_{u}$ and $U$ gave larger values of roughness than were obtained from the cup anemometer data. Since the sonic data set is much smaller and the roughness is only from a few weeks rather than the entire year, it cannot be used to determine a roughness for the entire year, but supports the use of the $\sigma_{E}$ method.

\subsection{Additional Roughness Estimates for SRS Operations Areas}

Roughness specific to each of the SRS operations areas are needed to support accident dose calculations for a facility's nearest co-located worker. Operations areas are relatively open and may contain several large structures such as the canyon or reactor buildings, one or two story supporting facilities, trailers, small sheds and huts, overhead pipes and other supporting infrastructure, as well as paved surfaces such as parking lots interspersed with open grassy areas. In some cases, the adjacent forest may be sufficiently close to the cleared area to contribute to roughness. The size and density of structures varies by area or by major facilities located within an individual area. Since representative turbulence data were not available, area-specific roughness was estimated using the EPA computer algorithm AERSURFACE. The EPA recommends the AERSURFACE algorithm for determining surface roughness length values needed by dispersion modeling applications supporting Clean Air Act compliance (EPA, 2008).

This algorithm uses U.S. Geological Survey digital National Land Cover Data (NLCD) for 1992, the most recent available dataset, to distinguish among 21 land cover types at a spatial resolution of $30 \mathrm{~m}$. A sample NLCD image for the Savannah River Site is shown in Fig. 4-1. Each land cover type is assigned a value of roughness length based on a review of estimated values or range of values found in published reports. A review of output from AERSURFACE indicates the prevailing land use classifications within the SRS operations areas were correctly identified as a combination of commercial/industrial $\left(z_{o}=0.8 \mathrm{~m}\right)$, transitional $\left(z_{o}=0.2 \mathrm{~m}\right)$, and evergreen or mixed forest ( $z_{o}=0.95$ to $1.3 \mathrm{~m}$ ). The 'transitional' classification is assigned to an area containing 
a mix of land cover classes. Although new structures have since been built and other structures removed since 1992, a review of 2007 imagery of the SRS indicates there has been little overall changes in the basic land use classifications that would affect the AERSURFACE estimates.

\section{$\underline{\text { AERSURFACE Calculations and Results }}$}

User inputs for AERSURFACE include a specification of the coordinates for the location to be assessed and the distance that defines the upwind fetch. AERSURFACE then calculates the roughness using an inverse-distance, weighted geometric mean of roughness values within the specified fetch obtained from the digitized NLCD data set. Results can be output by season and directional sector or averaged over season, sector or both. Fetch was set to the EPA recommended value of $1 \mathrm{~km}$, which is consistent with the distances calculated previously for the $\mathrm{H}, \mathrm{D}$, and $\mathrm{N}$ Area meteorological towers. The reference location for the calculation was chosen as a point approximating the center of the area containing the operations activity of interest. The ArcGIS software package was used to view imagery of the operations areas, visually select the appropriate reference location, and record the associated coordinates (in UTM) for input to AERSURFACE.

Roughness lengths averaged over all sectors and seasons were calculated for each of the seven primary operations areas at SRS (Table 4-1). Although the AERSURFACE user guide documentation indicates considerable care was given to selecting appropriate references for the roughness data, as noted previously, these sources typically contain very general estimates or a range of values for each land cover category. Due to these inherent uncertainties, the values in Table 4-1 are considered generally representative for the given location. A review of the seasonal results shows variations of no more than 5 percent. Most of the land use categories within the area of influence are commercial/industrial or transitional, which not be expected to have a seasonal dependence.

Table 4-1. Roughness estimates for primary SRS operations areas

\begin{tabular}{|c|l|c|}
\hline Area & \multicolumn{1}{|c|}{$\begin{array}{c}\text { Coordinates } \\
(\mathrm{UTM})\end{array}$} & $\begin{array}{c}\text { Avg. } \mathrm{z}_{\mathrm{o}} \\
(\mathrm{m})\end{array}$ \\
\hline $\begin{array}{l}\text { A-Area } \\
\text { (SRNL) }\end{array}$ & $\begin{array}{l}\mathrm{E}: 431396.0 \\
\mathrm{~N}: 3689587.0\end{array}$ & 0.7 \\
\hline F-Area & $\begin{array}{l}\mathrm{E}: 436917.0 \\
\mathrm{~N}: 3682548.0\end{array}$ & 0.6 \\
\hline H-Area & $\begin{array}{l}\mathrm{E}: 440182 \\
\mathrm{~N}: 3683208\end{array}$ & 0.6 \\
\hline S-Area & $\begin{array}{l}\mathrm{E}: 440418.0 \\
\mathrm{~N}: 3683994.0\end{array}$ & 0.5 \\
\hline K-Area & $\begin{array}{l}\mathrm{E}: 438254.0 \\
\mathrm{~N}: 3674626.0\end{array}$ & 0.5 \\
\hline L-Area & $\begin{array}{l}\mathrm{E}: 441764.0 \\
\mathrm{~N}: 3674634.0\end{array}$ & 0.4 \\
\hline E-Area & $\begin{array}{l}\mathrm{E}: 438247.0 \\
\mathrm{~N}: 3682921.0\end{array}$ & 0.3 \\
\hline
\end{tabular}


Figure 4-1. USGS land cover data for SRS for use in EPA's AERSURFACE algorithm.

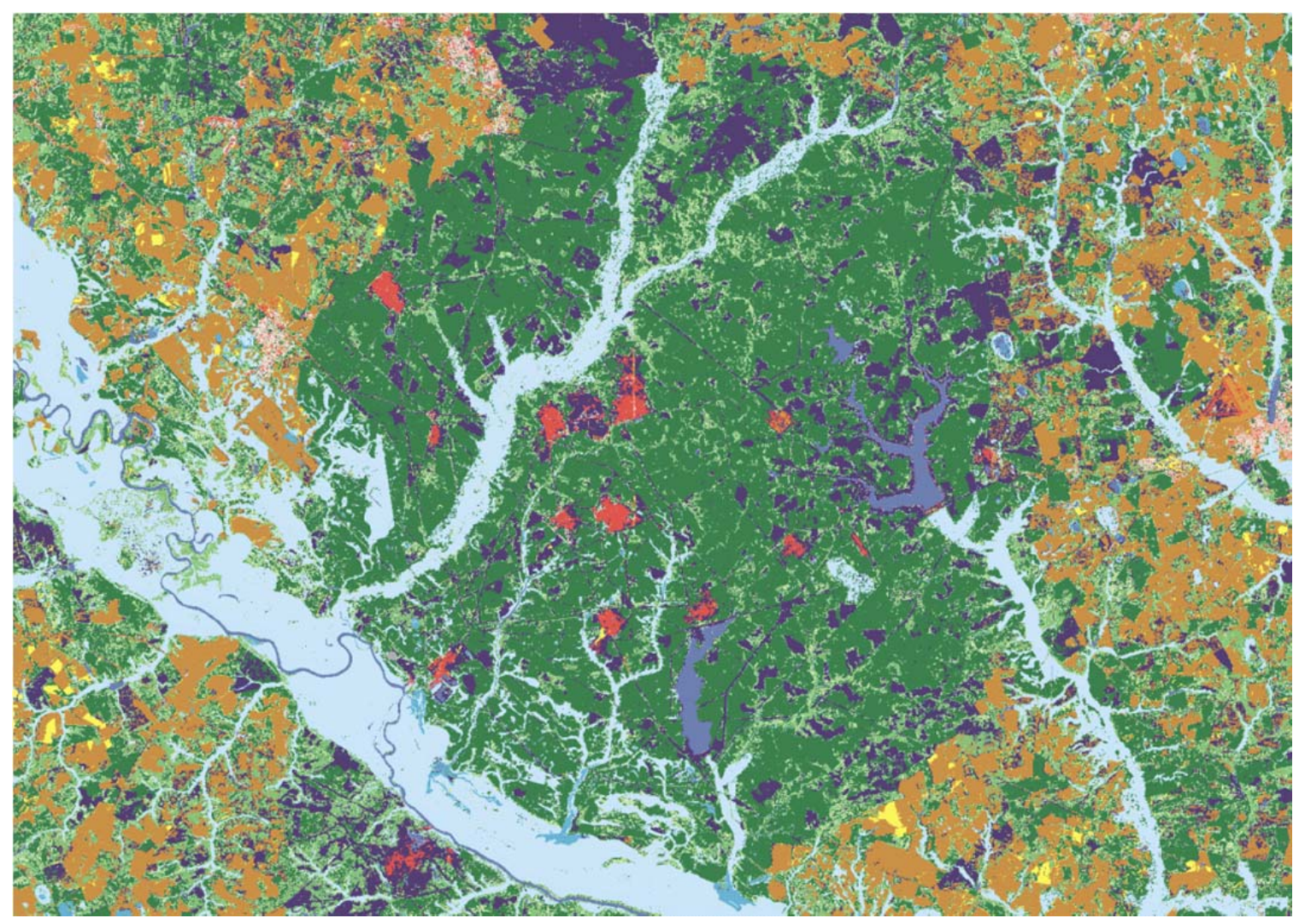

\subsection{Conclusions}

Surface roughness values characteristic of the prevailing forested terrain at SRS were calculated for the area surrounding the H-Area, D-Area, and N-Area meteorological towers by three methods: The first method is an estimation based on tree canopy height (Eq. 4) that was tested at multiple sites in Denmark; the second method is a computed roughness derived from the values of vertical turbulence intensities $\left(\sigma_{E}\right)$ for a one-year period (2010) using bivane data (Eq. 14); and the third method is a computed roughness based on values of friction velocity and wind speed using sonic anemometer data collected during short periods near sunrise and sunset for several days in 2010 (using Eq. 3).

Values of roughness calculated using $\sigma_{E}$ data from the H-Area tower ranged from $1.76 \mathrm{~m}$ to 1.86 $\mathrm{m}\left(95^{\text {th }}\right.$ percent confidence limits) with a median value of $1.81 \mathrm{~m}$. The roughness calculation using the $\sigma_{E}$ method had the advantage of using a large percentage of the data from the year 2010 and agreed with the roughness estimation based on tree canopy height. The sonic anemometer data method had the advantage of using a more fundamental equation for roughness, but was dependent on accepting the accuracy of its associated heat flux measurements to determine 
neutral conditions. Since the sonic anemometer was not being operated under the complete control of SRNL personnel, data quality could not be assured. Nonetheless, the sonic results were presented in this report for comparison.

Two factors may bias the roughness computations when using the $\sigma_{A}$ and $\sigma_{u}$ methods: (1) the relatively short sampling time of 15-min; and (2) known large-scale effects including terrain, clouds, vegetation, surface slope, soil moisture, and the height of the boundary layer in these computations. Boundary layer researchers including Andreas and Hicks (2002) and Tielman (1992) have thus added cautionary statements in their publications regarding the inapplicability of similarity theory for horizontal velocity standard deviations. For this reason, we gave much less credence to the calculations of roughness using the $\sigma_{A}$ and $\sigma_{u}$ methods.

\subsection{Recommendations}

A mean roughness of $1.8 \mathrm{~m}$, as calculated explicitly from the H-Area tower turbulence data, should be considered generally representative of SRS forested terrain and, therefore, suitable for use in dose calculations for the maximum offsite individual at the SRS boundary. The calculated values for the H-Area tower exhibit relatively little variance or directional dependence, suggesting a relatively uniform canopy for distances out to $1-2 \mathrm{~km}$. To evaluate the general applicability of these results across all forested areas of the Site, canopy height and composition were determined for randomly selected locations across the SRS using the USGS high-resolution lidar data set referenced previously (Poole, 2012). Each location was checked to ensure that the coordinates did not reside within a cleared operations area. Appendix B, Table B-1 summarizes the mean, $90^{\text {th }}$ percent, and $95^{\text {th }}$ percent canopy height, as well as canopy foliage composition, within a distance of 1000 feet of each selected location. The 'no foliage' results indicate dormant deciduous trees based on data collected during the winter season. Both canopy heights and composition for the H-Area tower location are within one standard deviation of the values for the randomly selected locations and are within one or two meters at many of the individual locations, indicating that the H-Area canopy is generally representative of the SRS forested landscape. Furthermore, the use of $1.8 \mathrm{~m}$ as a roughness adjustment in MACCS2 for vertical diffusion is conservative since the use of the $95^{\text {th }}$ percent canopy height in the determination of displacement height results in smaller calculated values of $\mathrm{z}_{0}$.

For dose calculations applicable to the co-located worker, operations area-specific values of roughness calculated with the EPA's AERSURFACE algorithm should be used. These values are summarized in Table 4-1. 


\subsection{References}

Andreas, E.L. and B.B. Hicks, 2002: Comments on "critical test of validity of Monin-Obukhov similarity during convective conditions”. Journal of the Atmospheric Sciences, 59, 26052607.

Arya, S.P., 2001: Introduction to Micrometeorology. Academic Press, San Diego CA, 415 pp.

Baldocchi, D.D. and T.P. Meyers, 1988: Turbulence structure in a deciduous forest canopy. Boundary Layer Meteorology, 43, 345-365.

Beljaars, 1987: On the memory of wind standard deviations to upstream roughness. Boundary Layer Meteorology, 38, 95-101.

Bowen, B.W., 2008: Analysis of turbulence profiles from three tall towers: departure from similarity theory in near-neutral and stable conditions. The Open Atmospheric Science Journal, 2, 106-116.

Briggs, G.A., 1973: Diffusion Estimation for Small Emissions, ATDL contribution File No 79, Atmospheric Turbulence and Diffusion Laboratory, NOAA, Oak Ridge, TN.

Crockford, A. and S-Y Hui, 2007: Wind Profiles and Forests - Validation of Wind Resource Assessment Methodologies Including the Effects of Forests, M.Sc. Thesis Project, Technical University of Denmark, Copenhagen, Denmark, 98pp.

EPA, 2000: Meteorological Monitoring Guidance for Regulatory Modeling Applications, EPA454/R-99-005, U.S. EPA, Office of Air Quality Planning and Standards, Research Triangle Park, NC 27711, Feb. 2000, 168pp.

EPA, 2008: AERSURFACE User's Guide, EPA-454/B-08-001, U. S. EPA, Office of Air Quality Planning and Standards, Research Triangle Park, NC.

Garrett, J.R., 1992: The Atmospheric Boundary Layer, Cambridge University Press, 316 pp.

Hicks, B.B., P. Hyson and C.J. Moore, 1975: A study of eddy fluxes over a forest, Journal of Applied Meteorology, 14, 58-66.

Irwin, J.S., 1980: Dispersion Estimate Suggestion \#8 (Internal memo), U.S. EPA, Office of Air Quality Planning and Standards, Research Triangle Park, NC 27711, Jul. 1980, 5 pp.

Irvine, M. R., B.A. Gardiner, and M. K. Hill, 1997: The evolution of turbulence across a forest edge, Boundary Layer Meteorology, 84, 467-496.

Kabela, E.D., 2011: Email from Anne R. Poole, USDA Forest Service - Savannah River, 09/07/2011, subject: canopy height.

Martano, P., 2000: Estimation of surface roughness length and displacement height from singlelevel sonic anemometer data. J. Applied Meteorology, 39, 708-715. 
McGaughey, R. J. and S. E. Reutebuck, 2009: Savannah River Site 2009 LIDAR Project, FY09 Final Report, Pacific Northwest Research Station, U. S. Forest Service, Seattle, WA.

Panofsky, H.A., 1984: Vertical variation of roughness length at the Boulder Atmospheric Observatory. Boundary Layer Meteorology, 28, 305-308.

Panofsky, H.A. and J.A. Dutton, 1984: Atmospheric Turbulence - Models and Methods for Engineering Applications. John Wiley and Sons, New York, 397 pp.

Parker, M.J. and R.P. Addis, 1993: Meteorological Monitoring Program (U), WSRC-TR-93-106, WSRC Savannah River Technology Center, Aiken, SC, 87 pp.

Poole, A. R., 2012: RE:Lidar-Derived Canopy Height Data, e-mail correspondence to C. H. Hunter, March 1, 2012.

Randerson, D.H. (editor), 1984: Atmospheric Science and Power Production, prepared for the USDOE, Office of Energy Research, Office of Health and Environmental Research,. Technical Information Center, USDOE., 850 pp.

Raupach, M.R., 1994: Simplified expressions for vegetation roughness length and zero-plane displacement as functions of canopy height and area index (research note). Boundary Layer Meteorology, 71 211-216.

Royal Aeronautical Society, 1972: Characteristics of wind speed in the lower layers of the atmosphere near the ground: Strong winds (neutral atmosphere). Eng. Sci. Data Unit, No. 72026, London.

Slade, D.H. (editor), 1968: Meteorology and Atomic Energy 1968, ESSA, Air Resources Laboratories, prepared for the USAEC. July, 1968, 445 pp.

Soegaard, H. N. O. Jensen, E. Boegh, C. B. Hasager, K. Schelde, A. Thomsen, 2003: Carbon dioxide exchange over agricultural landscapes using eddy correlation and footprint modeling, Agricul. and Forest Meteor. ,114, 153-173.

Tielman, H.W., 1992: Wind characteristics in the surface layer over heterogeneous terrain. Journal of Wind Engineering and Industrial Aerodynamics, 41-44, 329-340.

Weber, A.H., J.S. Irwin, J.P. Kahler and W.B. Petersen, 1975: Atmospheric Turbulence Properties in the Lowest 300 Meters. USEPA ESSRL, EPA-600/4-75-004, Research Triangle Park, North Carolina, USA. 153 pp. 


\section{Appendix A}

Table A-1. Pasquill-Gifford categories based on implementation of the EPA (2000) method of determining stability categories using modified values of $\sigma_{E}$ and $\sigma_{A}$ for site roughness and height.

\begin{tabular}{|l|l|l|l|l|l|l|l|}
\hline $\begin{array}{l}\text { PG } \\
\text { category }\end{array}$ & $\begin{array}{l}\text { Initial } \\
\text { lower } \\
\text { limit } \sigma_{E}\end{array}$ & $\begin{array}{l}\text { Initial } \\
\text { lower } \\
\text { limit } \sigma_{A}\end{array}$ & $\begin{array}{l}\text { Roughness } \\
\text { correction }\end{array}$ & $\begin{array}{l}\text { Height } \\
\text { correction } \\
\text { for } \sigma_{E}\end{array}$ & $\begin{array}{l}\text { Height } \\
\text { correction } \\
\text { for } \sigma_{A}\end{array}$ & $\begin{array}{l}\text { New } \\
\sigma_{E} \text { lower } \\
\text { limit }\end{array}$ & $\begin{array}{l}\text { New } \\
\sigma_{A} \text { lower } \\
\text { limit }\end{array}$ \\
\hline $\mathrm{A}$ & 11.5 & 22.5 & 1.64 & 1.03 & 0.92 & 19.46 & 33.89 \\
\hline $\mathrm{B}$ & 10.0 & 17.5 & 1.64 & 1.06 & 0.80 & 17.43 & 23.11 \\
\hline $\mathrm{C}$ & 7.8 & 12.5 & 1.64 & 1.01 & 0.78 & 13.01 & 16.03 \\
\hline $\mathrm{D}$ & 5.0 & 7.5 & 1.64 & 0.82 & 0.71 & 6.70 & 8.81 \\
\hline $\mathrm{E}$ & 2.4 & 3.8 & 1.64 & 0.64 & 0.57 & 2.51 & 3.59 \\
\hline $\mathrm{F}$ & 0.0 & 0.0 & 1.64 & 0.0 & 0.0 & 0.0 & 0.0 \\
\hline
\end{tabular}




\section{Appendix B}

Table B-1. Lidar derived canopy height and composition data for SRS. Height data represent mean, 90th percentile, and 95th percentile values. Percent foliage/no foliage represents data collected during the winter season.

\begin{tabular}{|c|c|c|c|c|c|}
\hline $\begin{array}{l}\text { Location } \\
\text { UTM (m) }\end{array}$ & $\begin{array}{c}\text { Mean Canopy } \\
\text { Height (m) }\end{array}$ & $\begin{array}{c}\text { Mean Height } \\
\text { p90 (m) }\end{array}$ & $\begin{array}{l}\text { Mean Height } \\
\text { p95 (m) }\end{array}$ & $\begin{array}{l}\text { Percent no } \\
\text { Foliage }\end{array}$ & $\begin{array}{l}\text { Percent } \\
\text { Foliage }\end{array}$ \\
\hline $\begin{array}{l}438695.9 \mathrm{E} \\
3691980.0 \mathrm{~N}\end{array}$ & 17.0 & 20.3 & 21.3 & 19.5 & 80.5 \\
\hline $\begin{array}{l}434034.0 \mathrm{E} \\
3688204.3 \mathrm{~N}\end{array}$ & 11.7 & 15.0 & 15.8 & 19.2 & 80.8 \\
\hline $\begin{array}{l}440273.0 \mathrm{E} \\
3687842.0 \mathrm{~N}\end{array}$ & 21.5 & 23.6 & 25.0 & 54.7 & 45.3 \\
\hline $\begin{array}{l}452053.0 \mathrm{E} \\
3688669.0 \mathrm{~N}\end{array}$ & 19.3 & 23.9 & 24.9 & 23.9 & 76.1 \\
\hline $\begin{array}{l}451213.0 \mathrm{E} \\
3681810.0 \mathrm{~N}\end{array}$ & 16.6 & 22.6 & 23.4 & 20.2 & 79.8 \\
\hline $\begin{array}{l}444561.0 \mathrm{E} \\
3678840.1 \mathrm{~N}\end{array}$ & 14.8 & 18.1 & 18.9 & 20.8 & 79.2 \\
\hline $\begin{array}{l}429462.2 \mathrm{E} \\
3684148.0 \mathrm{~N}\end{array}$ & 19.0 & 23.4 & 24.4 & 32.8 & 67.2 \\
\hline $\begin{array}{l}428183.0 \mathrm{E} \\
3679343.0 \mathrm{~N}\end{array}$ & 20.3 & 24.5 & 25.5 & 25.1 & 74.9 \\
\hline $\begin{array}{l}434719.0 \mathrm{E} \\
3672550.0 \mathrm{~N}\end{array}$ & 17.1 & 19.8 & 20.9 & 29.6 & 70.4 \\
\hline $\begin{array}{l}434719.0 \mathrm{E} \\
3667654.0 \mathrm{~N}\end{array}$ & 15.6 & 17.9 & 19.0 & 37.8 & 62.2 \\
\hline $\begin{array}{l}440415.1 \mathrm{E} \\
3665613.0 \mathrm{~N}\end{array}$ & 19.9 & 22.2 & 23.2 & 29.1 & 70.9 \\
\hline $\begin{array}{l}445220.0 \mathrm{E} \\
3670690.0 \mathrm{~N}\end{array}$ & 16.2 & 19.7 & 20.7 & 33.7 & 66.3 \\
\hline $\begin{array}{l}456722.0 \mathrm{E} \\
3672562.0 \mathrm{~N}\end{array}$ & 10.3 & 16.1 & 17.1 & 48.0 & 52.0 \\
\hline $\begin{array}{l}456722.0 \mathrm{E} \\
3672562.0 \mathrm{~N}\end{array}$ & 15.9 & 19.2 & 20.1 & 26.5 & 73.5 \\
\hline H-tower & 20.7 & 23.3 & 24.2 & 33.5 & 66.5 \\
\hline Average & 17.1 & 20.6 & 21.6 & 30.3 & 69.7 \\
\hline Stand. Dev. & 3.2 & 3.0 & 3.0 & 10.4 & 10.4 \\
\hline
\end{tabular}




\section{Distribution:}

D. E. Eyler, 773-A

J. C. Grove, 730-4B

A. E. Burris, 773-A

L. E. Johnson, 707-C

L. M. Chandler, 773-A

A. M. Vincent, 707-C

S. K. Elliott, 707-C

R. L. Buckley, 773-A

S. R. Chiswell, 773-A

R. J. Kurzeja, 773-A

M. J. Parker, 735-7A

B. J. Viner, 773-A

D. W. Werth, 773-A 